\title{
REXROTH, Frank, Das Milieu der Nacht. Obrigkeit und Randgruppen im spätmittelalterlichen London
}

\section{Martial Staub}

\section{OpenEdition}

\section{Journals}

Édition électronique

URL : http://journals.openedition.org/ifha/1351

DOI : 10.4000/ifha.1351

ISSN : 2198-8943

\section{Éditeur}

IFRA - Institut franco-allemand (sciences historiques et sociales)

\section{Référence électronique}

Martial Staub, «REXROTH, Frank, Das Milieu der Nacht. Obrigkeit und Randgruppen im spätmittelalterlichen London », Revue de l'IFHA [En ligne], Date de recension, mis en ligne le 01 janvier 1999, consulté le 22 septembre 2020. URL : http://journals.openedition.org/ifha/1351 ; DOI : https:// doi.org/10.4000/ifha. 1351

Ce document a été généré automatiquement le 22 septembre 2020.

(C)IFHA 


\title{
REXROTH, Frank, Das Milieu der Nacht. Obrigkeit und Randgruppen im spätmittelalterlichen London
}

\author{
Martial Staub
}

1 L'étude que Frank Rexroth présente sur le véritable »milieu de la nuit« qui se dessine dans les sources londoniennes relatives à la pauvreté et à l'asocialité aux XIVe et XVe ss. est courageuse. En effet, l'auteur s'y propose de prendre à bras le corps les interactions entre les représentations, l'imaginaire ou les mentalités, d'une part, et les formes de l'action ainsi que les institutions, d'autre part, qui déterminaient les marges dans une grande ville d'Occident à la fin du Moyen Âge. L'idée est de saisir la société en question, dans ce qui la constitue, par ce qu'elle exclut, sachant que cela est déterminé par la manière dont elle exclut. Cette dernière précision est d'importance en ce qu'elle ancre l'étude de Fr.R., une thèse d'Habilitation dirigée par Michael Borgolte à l'Université Humboldt de Berlin, dans la lignée des travaux récents d'histoire sociale attentifs aux »discours«. Fr.R. reste cependant en retrait par rapport à cette historiographie en ce qu'il ne peut en fin de compte se résigner à ne pas postuler la société dont il prétend pourtant montrer la constitution. Ce travers apparaît très nettement dans les références sociologiques de l'auteur, qui se situent toutes dans la mouvance durkheimienne, ignorant notamment les perspectives ouvertes, en Allemagne, par Niklas Luhmann, dont la sociologie repose précisément sur la dynamique d'inclusion et d'exclusion des systèmes sociaux. Mais, même à considérer la Sozialdisziplinierung, une conception, on le rappellera, développée par un historien, moderniste il est vrai, Fr.R. ne va pas aussi loin qu'il le pourrait. Il opère certes un déplacement, nécessaire, de l'État, auquel Gerhard Oestreich accordait incontestablement une place trop importante dans le processus de discipline sociale, vers la société civile. Mais celle-ci n'est pas perçue dans sa dimension historique, sans quoi l'attention aurait dû se porter sur les groupes sociaux au sein du monde urbain. On rappellera à ce propos que Michel Foucault a montré que, longtemps, c'est la famille qui excluait les fous. On entrevoit du reste tout le parti que les analyses de Fr.R. auraient, en raison même de leur étendue, pu tirer des réflexions de Michel Foucault. Or, sauf 
erreur de notre part, son nom n'apparaît à aucun moment, pas plus d'ailleurs que celui de Gerhard Oestreich. Aux lecteurs à qui ces remarques paraîtraient manquer de spécificité, on rappellera les résultats obtenus par l'analyse menée dès 1958 par Louis Chevalier, sur une base comparable à celle de Michel Foucault, sur les Classes laborieuses et classes dangereuses à Paris pendant la première moitié du XIXe siècle. Louis Chevalier a notamment pu montrer comment, pendant la période considérée, le petit peuple de Paris a fini par adopter l'image que les scientifiques et la population aisée se faisaient de lui, avec les conséquences sociales que l'on sait. Dans de telles conditions, la notion de "milieu « revêt une tout autre connotation, de l'efficacité et, donc, de la modernité de laquelle le travail de Fr.R. témoigne - à son corps défendant. Le Londres de Dickens et le Paris d'Hugo ou de Sue n'ont visiblement pas fini de hanter notre imaginaire! 